\title{
Endothelial Cell Spreading on Fibrin Requires Fibrinopeptide B Cleavage and Amino Acid Residues 15-42 of the $\beta$ Chain
}

\author{
Leslie A. Bunce, Lee Ann Sporn, and Charles W. Francis \\ Hematology Unit, Department of Medicine, University of Rochester School of Medicine \& Dentistry, Rochester, New York 14642
}

\begin{abstract}
Adhesion and spreading of cultured human umbilical vein endothelial cells on fibrin surfaces of varying structure were characterized to understand better the interactions occurring between endothelium and fibrin at sites of vascular injury. Fibrin prepared with reptilase, which cleaves only fibrinopeptide $A$ from fibrinogen, and fibrin prepared with thrombin, which cleaves both fibrinopeptide $A$ and fibrinopeptide $B$, equally supported endothelial cell adhesion. In contrast, only fibrin made with thrombin mediated endothelial cell spreading, as assessed by fluorescence microscopy of cells stained with rhodamine phalloidin to identify actin stress fibers or by scanning electron microscopy. Fibrin prepared with reptilase failed to support cell spreading. To further investigate the role of the amino terminus of the fibrin $\beta$ chain after fibrinopeptide $B$ cleavage in promoting cell spreading, protease III from Crotalus atrox venom was used to specifically cleave the amino-terminal 42 residues of the fibrinogen $B \beta$ chain. After clotting with thrombin, this fibrin derivative lacking $B \beta 1-42$ failed to support significant cell spreading. Spreading on fibrin was unaffected by depletion of Weibel-Palade bodies from endothelial cells, indicating that the spreading was independent of stimulated von Willebrand factor release. We conclude that endothelial cell spreading on fibrin requires fibrinopeptide $B$ cleavage and involves residues $15-42$ of the fibrin $\beta$ chain. (J. Clin. Invest. 1992. 89:842-850.) Key words: cell adhesion • cell spreading • endothelial cell $\bullet$ reptilase $\bullet$ thrombin
\end{abstract}

\section{Introduction}

Blood vessels are lined with a confluent monolayer of endothelial cells $(E C)^{1}$ that are polarized, with their luminal surface exposed to flowing blood and their abluminal side adherent to subendothelial matrix proteins. Cultured EC adhere and spread on purified, surface-bound glycoproteins found in the

Portions of this work have been published in abstract form (1990. Blood. 76:413a).

Address reprint requests to Dr. Francis, Hematology Unit, Box 610, University of Rochester Medical Center, 601 Elmwood Avenue, Rochester, NY 14642.

Received for publication 11 June 1991 and in revised form $12 \mathrm{No}$ vember 1991.

1. Abbreviations used in this paper: EC, endothelial cell; FPA, fibrinopeptide A; FPB, fibrinopeptide B; PPACK, D-phenylalanyl-L-prolyl-Larginyl-chloromethyl ketone; RGD, arginine-glycine-aspartic acid; vWf, von Willebrand factor.

J. Clin. Invest.

(c) The American Society for Clinical Investigation, Inc.

0021-9738/92/03/0842/09 \$2.00

Volume 89, March 1992, 842-850 subendothelium including fibronectin (1-3), collagen $(1,3)$, laminin (2-5), vitronectin $(1,6)$, thrombospondin $(7,8)$, and von Willebrand factor (vWf) $(6,9)$. Also, surfaces coated with fibrinogen mediate EC adhesion in vitro (1, 3, 9-11), although fibrinogen is primarily a plasma protein and not normally a component of the subendothelial matrix. Exposure of the subendothelium to fibrinogen occurs only with vessel injury which also causes activation of the coagulation system, resulting in conversion of plasma fibrinogen to fibrin. The interaction of EC with fibrin results in several effects including cell retraction and loss of cell organization $(12,13)$, separation of the monolayer into migratory cells (13), and release of vWf from WeibelPalade bodies (14). However, less is known about the mechanism mediating EC adhesion or spreading on fibrin, which is essential to the processes of wound healing and revascularization.

Adhesion and spreading of EC on protein substrates are related but separate cell functions. Adhesion is mediated through binding of transmembrane, heterodimer glycoprotein cell surface receptors, termed integrins, to specific sites on adhesive glycoproteins containing the tripeptide amino acid sequence, arginine-glycine-aspartic acid (RGD) (15). Endothelial cells express multiple integrins including $\alpha_{\mathrm{v}} \beta_{3}$, which mediates adhesion to a number of glycoproteins including vitronectin, thrombospondin, vWf, and fibrinogen $(6,7,9,16)$. Cell spreading requires initial adhesion, followed by cytoskeletal organization including the formation of stress fiber bundles composed of actin filaments. These actin filaments are connected to the plasma membrane through a sequence of cytoplasmic proteins which bind to the intracellular segment of the integrin receptor at the focal contact or adhesion plaque (17). Sequential cytoskeletal organizational changes including extrusion of lamellipodia adjacent to the site of injury, relocation of the centrosome, elongation of the cell in a polarized manner, and formation of actin stress fibers have been described in vitro at sites of endothelial injury (18). Such cytoskeletal changes contribute to spreading and migration, and they are important events in the response to vessel injury, as adherent EC adjacent to the damaged de-endothelialized area are stimulated to cover the exposed subendothelium or to revascularize fibrin clots.

In the present study we have investigated the structural features of fibrin required to mediate EC spreading, using several enzymes to prepare fibrin substrates varying in structure at critical locations. Thrombin cleaves fibrinogen at arg16-gly 17 of the $A \alpha$ chain and arg14-gly 15 of the $B \beta$ chain, resulting in rapid release of fibrinopeptide $A$ (FPA, A $\alpha 1-16$ ), and slower release of fibrinopeptide $B$ (FPB, B $\beta 1-14)$. This exposes sites at the new amino-terminal ends of the $\alpha$ and $\beta$ chains that mediate polymerization of the fibrin monomers. Reptilase, a snake venom protease from Bothrops atrox, cleaves only FPA, uncovering the polymerization site at the amino terminus of the $\alpha$ chain and resulting in formation of fibrin without FPB cleavage. Protease III from Crotalus atrox venom specifically re- 
moves $\mathrm{B} \beta 1-42$ from fibrinogen without affecting the $\mathrm{A} \alpha$ or $\gamma$ chains $(19,20)$. This modified fibrinogen (fibrinogen 325$)$ can then be clotted using thrombin or reptilase. We have characterized EC adhesion and spreading on these fibrins with different structures, and the results indicate that cell spreading, but not adhesion, requires cleavage of FPB and involves residues 1542 of the $\beta$ chain of polymerized fibrin.

\section{Methods}

Human fibrinogen (grade L) was obtained from KabiVitrum, Franklin, $\mathrm{OH}$, and co-purifying factor XIII was inactivated with acid-urea treatment as described elsewhere (21). Factor XIII inhibition was confirmed by demonstrating absence of cross-linked $\gamma$ chains by sodium dodecyl sulfate polyacrylamide gel electrophoresis (SDS PAGE) of the reduced polypeptide chains of fibrin, prepared after clotting with thrombin in the presence of $10 \mathrm{mM}$ calcium chloride. Co-purifying fibronectin in the fibrinogen was depleted by gelatin sepharose chromatography (22) (Pharmacia, Inc., Piscataway, NJ), and the fibrinogen-containing pool was further depleted of fibronectin by chromatography over a column of protein A Sepharose (Pharmacia, Inc.) to which rabbit polyclonal IgG anti-human fibronectin (Cappel, Organon Teknika Co., Durham, NC) was bound. Fibronectin concentration in fibrinogen preparations was measured by ELISA (American Diagnostica, Greenwich, CT; or American Bioproducts, Parsippany, NJ) and represented $<0.02 \%$ of total protein. Purified protease III, a coagulant protease from Crotalus atrox venom was kindly supplied by Dr. Andrei Budzynski, Temple University, Philadelphia, PA. Fibrinogen lacking residues 1-42 of the $B \beta$ chain, (fibrinogen 325), was prepared by incubation of fibrinogen (Kabi Vitrum) or fibronectin-depleted fibrinogen in buffer with protease III at an enzyme/substrate ratio of $1: 750$ at $37^{\circ} \mathrm{C}$ for $2 \mathrm{~h}$ as described $(19,20)$. The polypeptide chain composition of fibrinogen and fibrin was assessed by $7 \%$ SDS PAGE after disulfide bond reduction as described (23). Human thrombin $(3,250 \mathrm{U} / \mathrm{mg})$, which cleaves both FPA and FPB, and reptilase snake venom, which cleaves only FPA, were obtained from Calbiochem-Behring Corp., LaJolla, CA, and from American Diagnostica, respectively. For some experiments, thrombin was ${ }^{125}$ I radiolabeled using the lacto-peroxidase method (24) to a specific activity of $2.3 \times 10^{8} \mathrm{cpm} / \mathrm{mg}$, and the labeled thrombin retained $82 \%$ activity as determined by chromogenic assay using the chromogenic substrate H-D-phenylalanyl-L-pipecolyl-L-arginine-p-nitro-anilide dihydrochloride (S-2238, Kabi Vitrum).

Cell culture. Human umbilical vein EC were harvested as described elsewhere $(25,26)$, cultured in McCoy's 5A medium (TCN/Flow Laboratories, McLean, VA) with $20 \%$ fetal bovine serum, and passaged up to five times, although most experiments used second passage cells. Passaged cells were supplemented with $50 \mu \mathrm{g} / \mathrm{ml}$ EC growth supplement (Biomedical Technologies, Inc., Stoughton, MA) and $10 \mu \mathrm{g} / \mathrm{ml}$ heparin (Sigma Chemical Co., St. Louis, MO). Near-confluent cells were metabolically labeled overnight with $25 \mu \mathrm{Ci} / \mathrm{ml}$ of $\left.{ }^{35} \mathrm{~S}\right]$ cysteine $(1,153.4 \mathrm{Ci} / \mathrm{mol}$, New England Nuclear Research Products, Boston, MA) in complete culture medium. EC suspensions used in adhesion and spreading studies were prepared by trypsinization of the monolayers. Cells were suspended by rinsing in Hank's balanced salt solution (HBSS) followed by brief incubation with trypsin-EDTA (Gibco Life Technologies, Inc., Grand Island, NY) and diluted 1:1 with HBSS (final concentration, $0.125 \%$ trypsin, $0.25 \mathrm{mM}$ EDTA). This was followed by centrifugation $(300 \mathrm{~g}, 5 \mathrm{~min})$ and resuspension three times using McCoy's 5A medium in the absence of serum. The EC were resuspended to an approximate concentration of $2 \times 10^{5}$ cells $/ \mathrm{ml}$. Primary human foreskin fibroblasts were prepared by finely mincing a newborn foreskin, digesting for $30-90 \mathrm{~min}$ in trypsin-EDTA at $37^{\circ} \mathrm{C}$ and plating of resulting cell suspension in a $25-\mathrm{cm}^{2}$ cell culture flask. Studies were conducted using fibroblast cultures at less than two passages.

Cell adhesion. 1-ml wells of 24-well cell culture plates (Corning Glass Works, Corning, NY), were coated by incubation with $0.4 \mathrm{ml}$ of
$30 \mu \mathrm{g} / \mathrm{ml}$ human plasma fibronectin, $60 \mathrm{mg} / \mathrm{ml}$ bovine serum albumin (BSA) (both from Sigma Chemical Co.), or $3 \mathrm{mg} / \mathrm{ml}$ fibrinogen, each dissolved in McCoy's 5A medium for at least $30 \mathrm{~min}$ and not longer than $18 \mathrm{~h}$ at $25^{\circ} \mathrm{C}$. The concentration of $30 \mu \mathrm{g} / \mathrm{ml}$ of fibronectin was chosen because preliminary experiments indicated that this resulted in maximal EC adhesion and spreading. Surfaces exposed to a concentration of $60 \mathrm{mg} / \mathrm{ml} \mathrm{BSA}$ supported minimal EC interaction. The concentration of $3 \mathrm{mg} / \mathrm{ml}$ fibrinogen was the same as that used to prepare fibrin. To prepare fibrin, $0.4 \mathrm{ml}$ fibrinogen $(3 \mathrm{mg} / \mathrm{ml}$ in McCoy's $5 \mathrm{~A}$ medium) was incubated at $25^{\circ} \mathrm{C}$ in a single well with $2.5 \mathrm{U} / \mathrm{ml}$ thrombin or $0.5 \mathrm{U} / \mathrm{ml}$ reptilase, or both, resulting in formation of a firm clot 2 $\mathrm{mm}$ thick. Higher concentrations of reptilase resulted in unwanted $\mathrm{A} \alpha$ chain degradation. Wells were used after $0.5 \mathrm{~h}$ of incubation at $25^{\circ} \mathrm{C}$ or stored at $25^{\circ} \mathrm{C}$ for up to $18 \mathrm{~h}$. Before exposure to cells, wells were washed one time with McCoy's $5 \mathrm{~A}$ medium, and then $2 \mathrm{U} / \mathrm{ml}$ hirudin (Sigma Chemical Co.), a leech-derived high-affinity thrombin inhibitor (27), or $1 \mu \mathrm{g} / \mathrm{ml}$ D-phenylalanyl-L-prolyl-L-arginyl-chloromethyl ketone (PPACK) (Bachem California, Torrence, CA), a synthetic, highly specific thrombin inhibitor $(27,28)$, both in McCoy's $5 \mathrm{~A}$ medium, was added to the wells and incubated at $25^{\circ} \mathrm{C}$ for $30 \mathrm{~min}$ to inactivate residual thrombin. The solutions were removed, the wells washed three times with McCoy's 5A medium, and an aliquot of $0.4 \mathrm{ml}$ of radiolabeled EC suspension was added to each well and incubated for $2 \mathrm{~h}$ at $37^{\circ} \mathrm{C}$. The unbound cells were then removed by aspiration followed by three washings. Adherent cells were then removed by trypsinization, and the percent adhesion cells was calculated as radioactive counts in adherent samples divided by the sum of the counts in adherent and unbound cell samples. All percentages represent the means of 4-10 determinations.

Cell spreading. Glass slides coated with protein solution or fibrin were prepared on Lab-Tek eight-chamber slides (Nunc, Napersville, IL). Fibrin coating was performed by adding $0.5 \mathrm{U} / \mathrm{ml}$ thrombin or 0.5 $\mathrm{U} / \mathrm{ml}$ reptilase or both to $0.25 \mathrm{ml}$ of $3 \mathrm{mg} / \mathrm{ml}$ of fibrinogen or fibrinogen 325 in buffer at $25^{\circ} \mathrm{C}$, followed several seconds later by aspiration of excess solution before solid clot formation, thus leaving a residual fibrin coating on the slides. Coating of slides with protein solutions was carried out using $30 \mu \mathrm{g} / \mathrm{ml}$ fibronectin, $60 \mathrm{mg} / \mathrm{ml} \mathrm{BSA}$, or $3 \mathrm{mg} / \mathrm{ml}$ fibrinogen in McCoy's buffer for $1-18 \mathrm{~h}$ at $25^{\circ} \mathrm{C}$. Slides were washed once with McCoy's buffer and then incubated with $0.25 \mathrm{ml}$ of $2 \mathrm{U} / \mathrm{ml}$ hirudin or $1 \mu \mathrm{g} / \mathrm{ml}$ PPACK in McCoy's buffer for $30 \mathrm{~min}$ at $25^{\circ} \mathrm{C}$ to inactivate residual thrombin and washed three times in McCoy's $5 \mathrm{~A}$ medium. Aliquots of $0.25 \mathrm{ml}$ of EC suspension were then added to the wells and incubated for $2 \mathrm{~h}$ at $37^{\circ} \mathrm{C}$. Adherent cells were fixed for 20 min in $3.7 \%$ formaldehyde in phosphate-buffered saline (PBS), permeabilized for $15 \mathrm{~min}$ in $0.5 \%$ Triton X-100 in PBS, and stained for F-actin with rhodamine-phalloidin (Molecular Probes, Inc., Eugene, OR) at a dilution of 1:10 for $30 \mathrm{~min}$. Coverslips were then mounted onto glass slides and spreading was evaluated by fluorescence microscopy. A minimum of 50 cells was examined by an observer blinded to the protein substrate present. Cells were scored as spread if they showed organized actin stress fibers present as microfilament bundles traversing most of the length of the cell in an orderly, parallel array. Round cells and those with sparse, actin strands were classified as unspread. All spreading percentages represent the mean of 4-10 determinations except where specified. Cell spreading was also evaluated using light microscopy on thicker fibrin clots prepared for the adhesion assay. For scanning electron microscopy, fibrin-coated plastic coverslips were incubated with suspensions of EC at $37^{\circ} \mathrm{C}$ for $2 \mathrm{~h}$ as above, and the cells were fixed in $1 \%$ glutaraldehyde in Sorensen's buffer for $1 \mathrm{~h}$, rinsed with buffer, then postfixed in $1 \%$ osmium tetroxide for $1 \mathrm{~h}$, and rinsed again. They were then dehydrated in a graded ethanol series and critical point dried, coated with gold, and observed with a scanning electron microscope (model T330A, JEOL USA, Inc., Peabody, MA).

Depletion of Weibel-Palade body content of endothelial cells. Second passage EC cultured to $70 \%$ confluency were incubated for $3 \mathrm{~d}$ in 5 , 10 , and $25 \mathrm{mM}$ ammonium chloride in complete culture medium with or without $\left[{ }^{35} \mathrm{~S}\right]$ cysteine $(25 \mu \mathrm{Ci} / \mathrm{ml})$. To determine Weibel-Palade body content of control and treated cells, indirect immunofluorescence 
staining of cells with anti-von Willebrand factor antiserum was performed as previously described (24). vWf was immunopurified from cell lysates or culture medium samples using previously described methods (29). The immunopurified vWf was electrophoresed on SDS $2 \%$ agarose gels (30) and the multimeric composition was determined after autoradiography.

Statistics. Comparison of means was performed using the twotailed Student's $t$ test. Variance is described as \pm SEM.

\section{Results}

EC plated onto fibrin made with thrombin were well-spread after $2 \mathrm{~h}$ showing clearly defined stress fibers traversing the cell in a bidirectional orientation and extending to the leading edge of the cell (Fig. $1 a$ ). In contrast, cells remained unspread on fibrin prepared with reptilase (Fig. $1 b$ ), and appeared smaller and lacked organized stress fibers. In the unspread cells, some actin filaments were noted with no apparent orientation at the cell periphery, and there were occasional small bleblike projections extending from the cell surface. A similar spreading pat- tern on the two types of fibrin was observed with early passage fibroblasts (not shown). These findings were confirmed by scanning electron microscopy which showed that EC on thrombin-made fibrin were well spread with several long filamentous surface projections extending from the cell (Fig. $2 a$ ). The unspread EC on fibrin made with reptilase showed no orientation and were more spherical with small spikelike projections extending from their surface in many directions (Fig. 2 $b$ ). The fine fibrillar background of the fibrin surface made with thrombin or reptilase was seen, and occasional larger fibrin bundles were present. The difference in spreading pattern was also observed by light microscopy with EC plated on 2-mmthick clots.

Cell spreading was quantitated as the percent of adherent cells showing well-defined stress fiber development (Fig. 3). Spreading of $70 \pm 4 \%$ of EC occurred on fibrin made with thrombin, and this was significantly greater than the $3 \pm 2 \%$ spreading of cells adherent to fibrin prepared with reptilase ( $P$ $<0.0005$ ). Fibrin prepared initially with reptilase and then incubated with thrombin resulted in a clot surface promoting
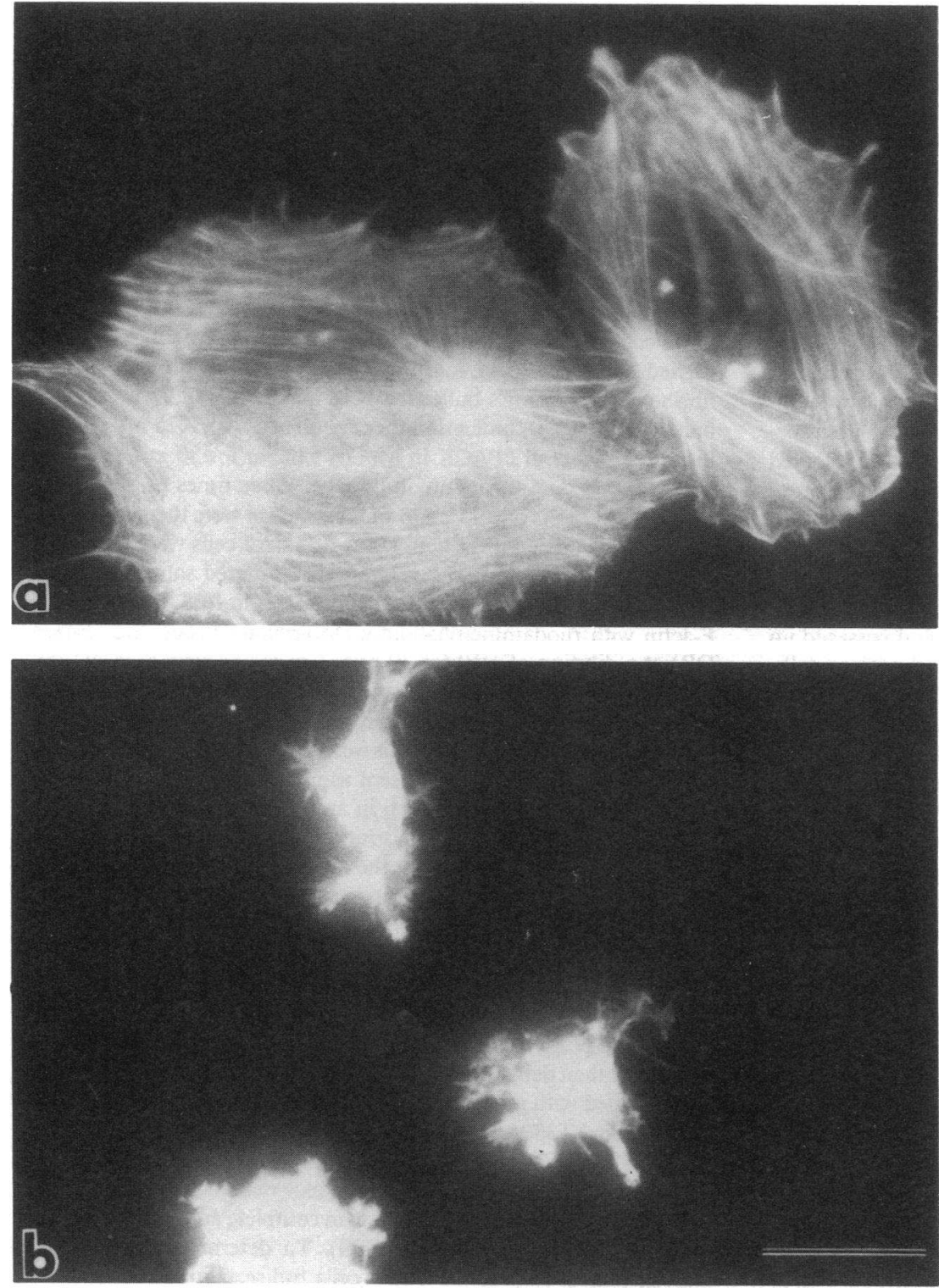

Figure 1. Fluorescent micrograph of EC stained for F-actin with rhodamine phalloidin. Slides were coated with fibrin by brief incubation with fibrinogen $(3 \mathrm{mg} / \mathrm{ml})$, and either thrombin $(0.5$ $\mathrm{U} / \mathrm{ml})$ or reptilase $(0.5 \mathrm{U} / \mathrm{ml})$. A suspension of $\mathrm{EC}$ was then added and incubated for $2 \mathrm{~h}$ at $37^{\circ} \mathrm{C}$. Adherent cells were fixed, permeabilized, and stained for F-actin using rhodamine phalloidin. (a) Well-spread EC on fibrin prepared with thrombin have organized actin stress fibers extending across the cells in a parallel array. (b) EC unspread on fibrin prepared with reptilase, shown at the same magnification as $a$, exhibit an absence of organized stress fibers and reduced cell area. Bar, $10 \mu \mathrm{m}$. 

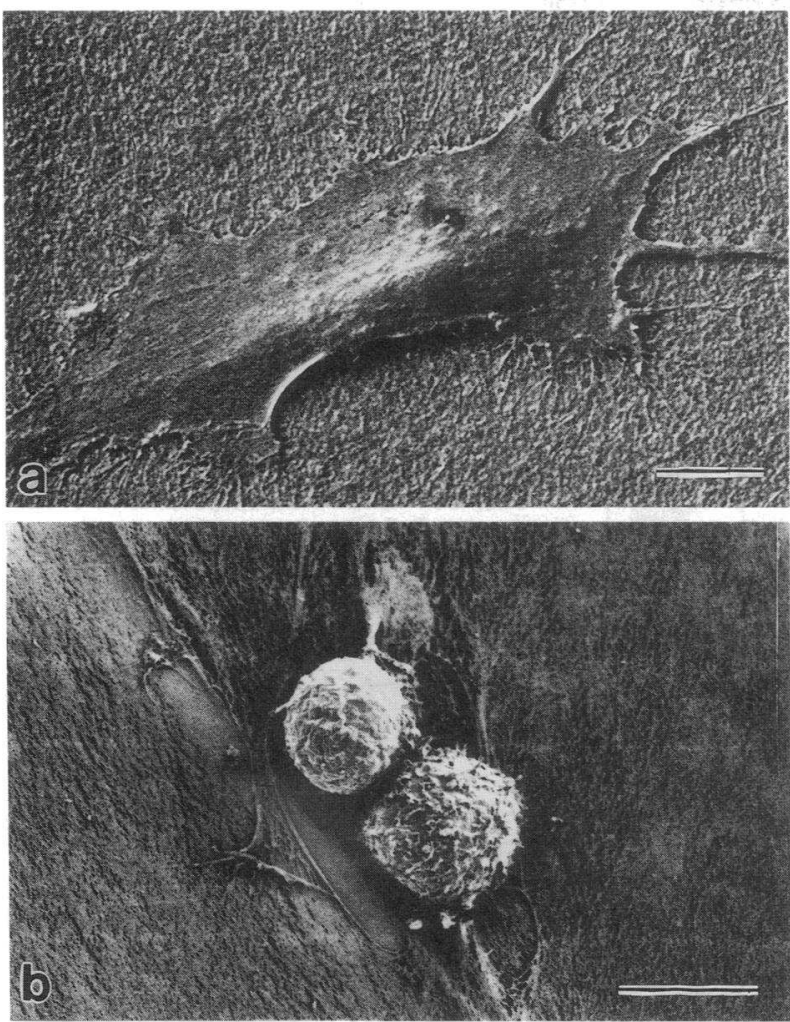

Figure 2. Scanning electron micrographs of EC on fibrin. EC were incubated on plastic coverslips coated with fibrin, fixed in $1 \%$ glutaraldehyde, postfixed in $1 \%$ osmium tetroxide, coated with gold, and examined by scanning electron microscopy. (a) Well-spread EC on thrombin-made fibrin shows bidirectional orientation of the cell with long filamentous projections and a fibrillar background. (b) Spherical, nonspread EC on fibrin prepared with reptilase exhibit a nonpolar orientation with small, randomly oriented surface spikes. Original magnification was $\times 2000$. Bars, $10 \mu \mathrm{m}$.

spreading of $57 \pm 4 \%$ of EC, comparable to that found on fibrin made with thrombin alone. However, when fibrin made with reptilase was incubated with thrombin inactivated by hirudin, there was only $2 \pm 1 \%$ spreading. Similarly, addition of thrombin inactivated with PPACK to fibrin prepared with reptilase resulted in $1 \pm 1 \%$ EC spreading in comparison to fibrin prepared with active thrombin and reptilase which promoted $52 \pm 8 \%$ spreading in paired experiments. There was no significant difference between EC adhesion on thrombin-made fibrin and reptilase-made fibrin (Fig. 3). EC were also tested for adhesion and spreading on control substrate coatings of BSA (60 $\mathrm{mg} / \mathrm{ml})$, fibronectin $(30 \mu \mathrm{g} / \mathrm{ml})$, and fibrinogen $(3 \mathrm{mg} / \mathrm{ml})$. There was $3 \pm 1 \%$ adhesion and $0 \%$ spreading of EC on a BSA coated surface, $43 \pm 3 \%$ adhesion and $93 \pm 2 \%$ spreading on the fibronectin coated surface and $21 \pm 2 \%$ adhesion and $32 \pm 10 \%$ spreading on the fibrinogen-coated surface.

The polypeptide chain composition of the various fibrin preparations was characterized by SDS PAGE (Fig. 4). Fibrin prepared with thrombin (lane 3 ) showed more rapid migration of the $\alpha$ and $\beta$ chains compared to the $A \alpha$ and $B \beta$ chains of fibrinogen (lane 2), confirming cleavage of FPA and FPB. Fibrin made with reptilase (lane 4 ) demonstrated cleavage of only FPA, while there was no change in the $\mathrm{B} \beta$ chain migration. The combination of both reptilase and thrombin (lane 5)

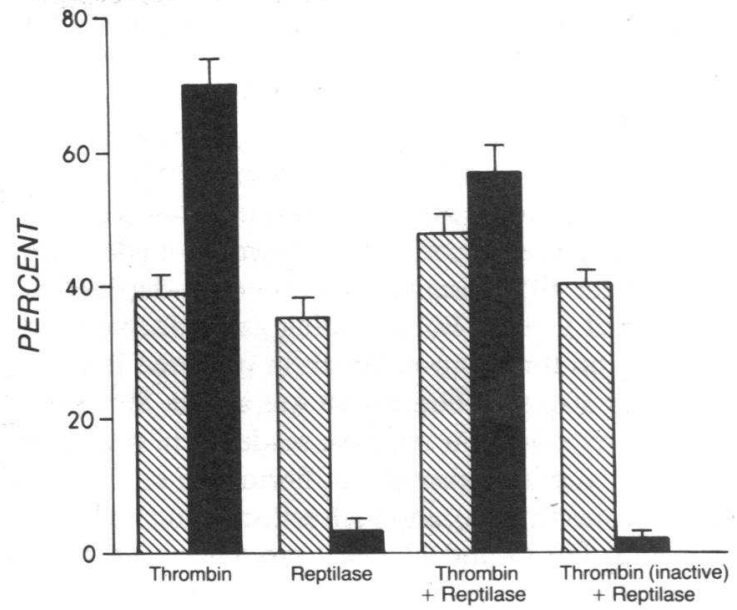

Figure 3. EC adhesion and spreading on fibrin surfaces. Adhesion (cross-hatched bars) was measured using $\left[{ }^{35} \mathrm{~S}\right]$ cysteine metabolically labeled cells, and spreading (solid bars) was quantitated as the percentage of adherent cells showing, by fluorescence microscopy, wellformed stress fibers after staining with rhodamine phalloidin. Both adhesion and spreading were measured after a 2-h incubation of EC suspension on the fibrin surface at $37^{\circ} \mathrm{C}$. Spreading on fibrin prepared with reptilase or reptilase plus inactive thrombin was significantly less $(P<0.0005)$ than spreading on fibrin prepared with thrombin or thrombin plus reptilase.

resulted in cleavage of both FPA and FPB, whereas fibrin prepared with a combination of hirudin-inactivated thrombin and reptilase (lane 6) showed cleavage of FPA alone. None of the fibrin preparations showed evidence of cross-linking when compared with the fibrin standard (lane 1 ) that exhibited complete cross-linking of $\gamma$ chains to dimers and some $\alpha$ chain cross-linking to high molecular weight forms.

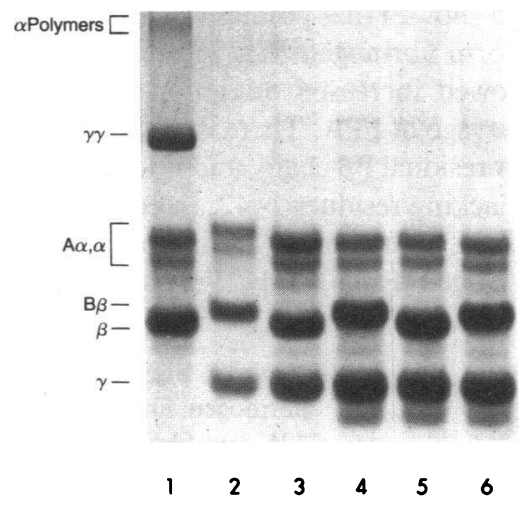

Figure 4. SDS PAGE of fibrinogen and fibrin prepared using thrombin, reptilase, or both. Samples of $10 \mu \mathrm{g}$ were electrophoresed on a $7 \%$ SDS polyacrylamide gel after disulfide bond reduction, and the gel was stained with Coomassie Blue. The location of polypeptide chains is shown and their identity indicated in comparison with standards of crosslinked fibrin (lane 1 )

and fibrinogen (lane 2). Lane 3, fibrin prepared with thrombin showing faster migration of the $\alpha$ and $\beta$ chains resulting from cleavage of FPA and FPB, respectively. Lane 4, fibrin prepared with reptilase showing cleavage of FPA only. Lane 5, fibrin prepared with both reptilase and thrombin showing cleavage of both FPA and FPB. Lane 6 , fibrin prepared with a combination of reptilase and hirudin-inactivated thrombin showing cleavage of FPA only but no change in the $\mathrm{B} \beta$ band. The $\gamma$ chain was monomeric in each case with no evidence of cross-linking to the dimer form in comparison with the crosslinked fibrin in lane 1 . The purified plasma fibrinogen contained a minor amount of carboxyl-terminal $\mathrm{A} \alpha$ chain degradation resulting in heterogenicity of the $A \alpha$ chains. 
Gelatin sepharose chromatography and immunoadsorption were used to reduce the fibronectin concentration to $<0.6$ $\mu \mathrm{g} / \mathrm{ml}$ in the fibrinogen solutions used to prepare clots. To determine whether an increase in fibronectin content of clots would cause an increase in cell spreading, purified fibronectin $(30 \mu \mathrm{g} / \mathrm{ml})$ was added to the fibrinogen solutions used to prepare fibrin clots. In paired experiments, thrombin-made fibrin prepared from factor XIII-inactivated, fibronectin-depleted fibrinogen supported $91 \pm 4 \%$ EC spreading as compared with $80 \pm 4 \%$ spreading on thrombin-made fibrin prepared from fibrinogen to which $30 \mu \mathrm{g} / \mathrm{ml}$ fibronectin was added. Similarly, there was no EC spreading on reptilase-made fibrin $(0 \%)$ and on fibrin made by reptilase cleavage of fibrinogen containing supplemental fibronectin ( $0 \%$ ), although cell adhesion was similar on both clots at $55 \pm 3 \%$ and $52 \pm 2 \%$, respectively. Additionally, treatment of fibronectin $(30 \mu \mathrm{g} / \mathrm{ml})$ by $0.5 \mathrm{U} / \mathrm{ml}$ of reptilase resulted in a coating which promoted $97 \pm 2 \% \mathrm{EC}$ spreading similar to the $94 \pm 1 \%$ EC spreading observed on glass surface coated with untreated fibronectin. Thus, reptilase treatment did not decrease EC spreading on a coating of fibronectin, and the presence of fibronectin did not influence EC spreading on uncrosslinked fibrin prepared with either enzyme.

The marked difference in cell spreading on fibrin prepared with reptilase compared to that made with thrombin indicated that cleavage of FPB was required and suggested a role for the new amino terminus of the fibrin $\beta$ chain that is exposed after FPB cleavage. To evaluate the role of the $\beta$ chain amino terminus, protease III from Crotalus atrox venom was used to selectively remove residues $1-42$ from the $B \beta$ chain of fibrinogen. This modified fibrinogen (fibrinogen 325 ) mediated EC spreading of adherent cells to the same degree as that seen using undegraded fibrinogen or fibrinogen containing supplemental fibronectin $(30 \mu \mathrm{g} / \mathrm{ml})$ when coated on wells (not shown). Fibrinogen 325 was clotted by cleavage of FPA with either reptilase or with thrombin to form fibrin which lacked $B \beta 1-42$ (fibrin 325). The structural modifications were confirmed by SDS PAGE (Fig. 5), which showed that protease III selectively cleaved the $\mathrm{B} \beta$ chain to form fibrinogen 325 . Fibrin 325 prepared with thrombin showed increased migration of the $\alpha$ chains consistent with cleavage of FPA. There was also cleavage of FPB from the minor residual $B \beta$ chain, and no change in migration of the $\beta$ chain lacking residues $1-42$. In contrast to the $70 \pm 5 \%$ spreading of EC adherent to fibrin made with thrombin from intact fibrinogen (Fig. 6 ), only $19 \pm 5 \%$ of adher-

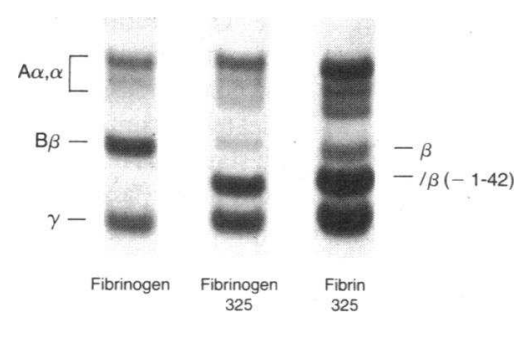

Figure 5. SDS PAGE of fibrinogen, fibrinogen 325 , and fibrin 325 . Samples of $10 \mu \mathrm{g}$ were electrophoresed on SDS $7 \%$ polyacrylamide gels after disulfide bond reduction and stained with Coomassie Blue. Fibrinogen 325, pre-

pared by incubation of fibrinogen with protease III of Crotalus atrox, contained a small amount of residual $B \beta$ chain but a predominance of the cleaved form lacking the amino-terminal 42 residues (B $\beta 1-42)$. Fibrin 325 prepared with thrombin showed more rapid migration of the $\alpha$-chain band owing to cleavage of FPA and increased migration of the residual $\beta$ chain band owing to FPB cleavage. No change in migration of the $/ \beta(-1-42)$ derivative occurred after thrombin treatment.

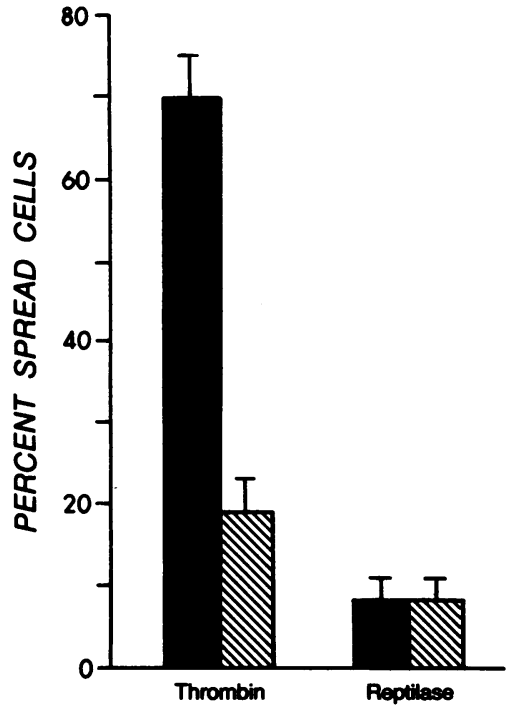

Figure 6. EC spreading on fibrin and fibrin 325. Glass slides were coated with fibrin prepared from purified fibrinogen (solid bars) or from fibrinogen 325 (crosshatched bars), prepared with protease III to remove $B \beta 1-42$. After incubating the fibrin surfaces with hirudin, they were overlaid with an EC suspension at $37^{\circ} \mathrm{C}$ for $\mathbf{2} \mathrm{h}$, fixed, permeabilized, and stained with rhodamine phalloidin, and the spreading was determined by fluorescence microscopy.

ent EC spread on fibrin 325 prepared by thrombin ( $P$ $<0.0001)$. There was minimal $(8 \pm 3 \%)$ spreading on fibrin prepared with reptilase cleavage of either intact fibrinogen or fibrinogen 325 . The $19 \pm 5 \%$ spreading on fibrin 325 prepared with thrombin was slightly greater than spreading on reptilasemade fibrin $325(8 \pm 3 \%)$ and was consistent with the small amount of residual uncleaved $\beta$ chain in the fibrin 325 preparation (Fig. 5). This difference in cell spreading on the two surfaces, however, was not statistically significant. These results indicate that the new amino terminus of the $\beta$ chain exposed after FPB cleavage is involved in mediating EC spreading, since fibrin lacking $\beta 15-42$ prepared with either reptilase or thrombin was minimally active.

To determine if the same amount of thrombin was present in the surfaces coated with fibrin 325 and intact fibrin, coverslips were prepared using fibrinogen 325 or fibrinogen clotted with radiolabeled thrombin. After washing, the coverslips coated with fibrin 325 contained $0.7 \%$ of total radiolabeled thrombin initially added to each well, and coverslips coated with fibrin prepared from undegraded fibrinogen incorporated $0.9 \%$ of total thrombin, indicating that the difference in EC spreading observed between fibrin 325 and fibrin was not due to a difference in the amount of thrombin incorporated. A similar approach was used to compare the incorporation of active thrombin and thrombin inactivated by PPACK into fibrin used to coat coverslips. The amount of radiolabeled thrombin incorporated into fibrin prepared with active thrombin alone was the same as that amount incorporated into fibrin prepared with reptilase plus PPACK-inactivated thrombin, indicating that the active site was not needed for binding.

To determine whether FPB, after cleavage by thrombin, promoted EC spreading, we prepared reptilase-made fibrin from fibrinogen supplemented with FPB. Factor XIII-inactivated, fibronectin-depleted fibrinogen $(7 \mathrm{mg} / \mathrm{ml})$ was first clotted with thrombin $(6 \mathrm{U} / \mathrm{ml})$, and the clot liquor, containing FPA and FPB, was expressed. Hirudin or PPACK was then added to the clot liquor to inactivate any residual thrombin. This clot liquor was then added to soluble fibrinogen, at a clot liquor/fibrinogen volume ratio of $1: 0.7$, for a final fibrinogen concentration of $3 \mathrm{mg} / \mathrm{ml}$. Reptilase $(0.5 \mathrm{U} / \mathrm{ml})$ was then 

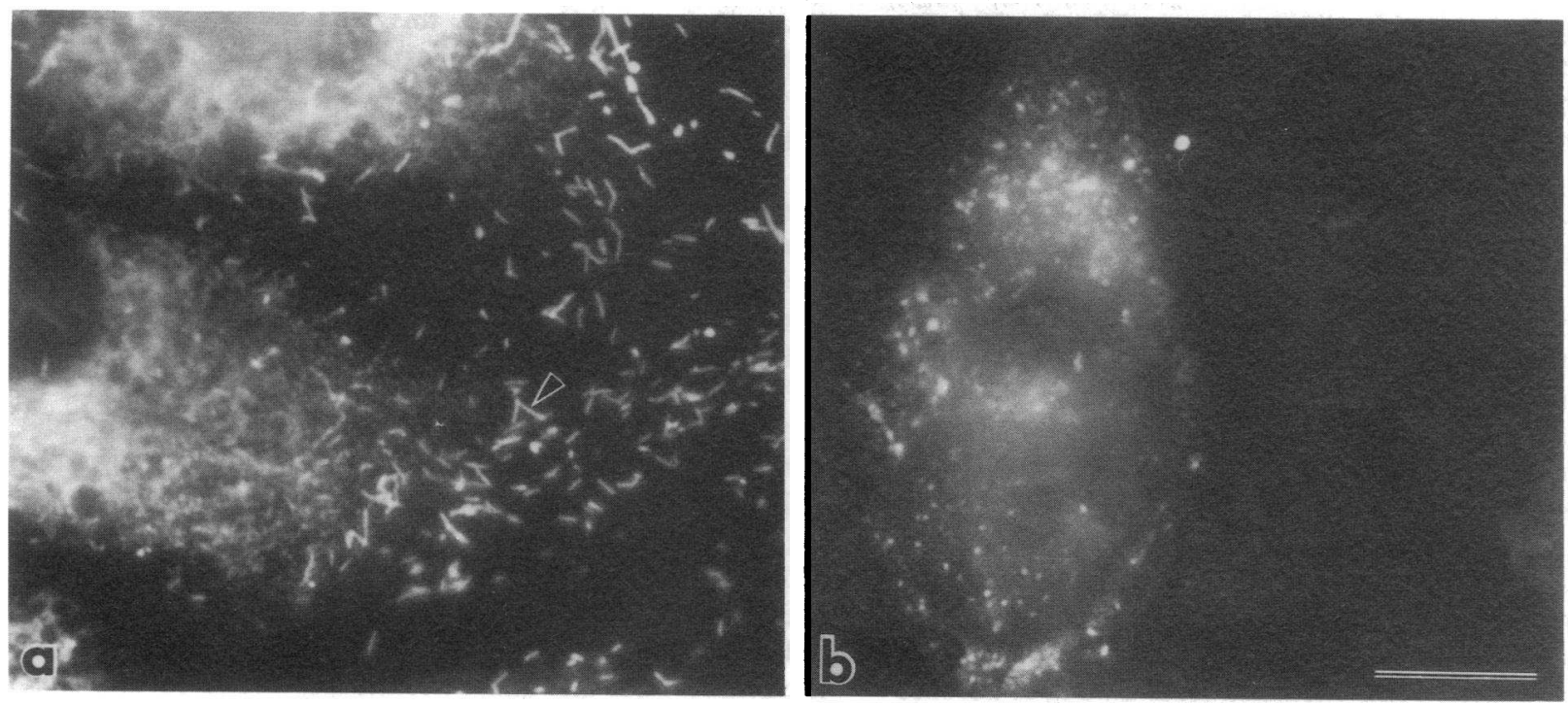

Figure 7. Immunofluorescence staining of EC for vWf cultured in the absence or presence of ammonium chloride. After permeabilization and fixation, cells were incubated with monoclonal anti-vWf antibody followed by rhodamine-labeled goat anti-mouse antibody and observed for fluorescence. (a) Untreated EC had numerous cytoplasmic rod-shaped Weibel-Palade bodies (arrowhead), whereas (b) those cultured in $25 \mathrm{mM}$ ammonium chloride contained no Weibel-Palade bodies. Bar, $10 \mu \mathrm{m}$.

added to this fibrinogen preparation containing the clot liquor to form a fibrin surface. In duplicate experiments, the reptilasemade fibrin surface, containing clot liquor from the previously thrombin-made fibrin, supported EC spreading of $9 \pm 3 \%$ which was similar to the $8 \pm 2 \%$ EC spreading seen on reptilase-made fibrin which did not contain thrombin-made clot liquor.

EC contain a pool of high molecular weight vWf, stored in specialized vesicles called Weibel-Palade bodies, that can be released after exposure of the cells to fibrin. To investigate the possibility that release of this $\mathrm{vWf}$ could play a role in mediat-

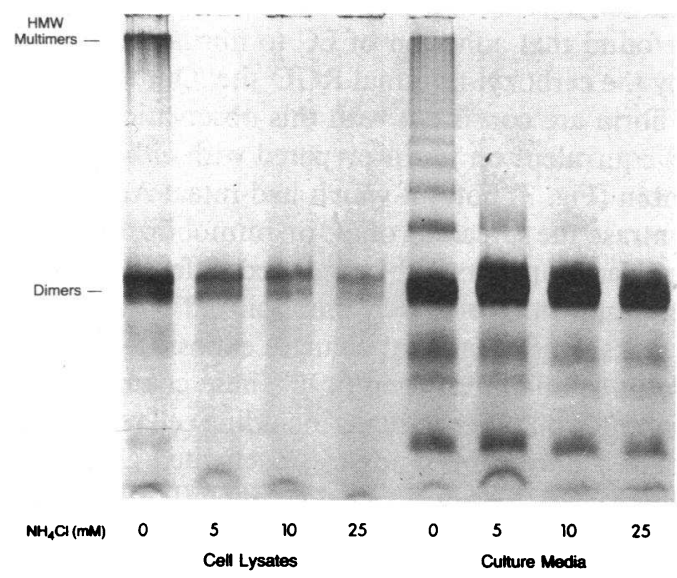

Figure 8. SDS agarose electrophoresis of vWf in EC lysates and culture media. EC were incubated for $3 \mathrm{~d}$ in control media $(O)$ or in 5 , 10 , or $25 \mathrm{mM}$ ammonium chloride in the presence of $\left[{ }^{35} \mathrm{~S}\right]$ cysteine. vWf was immunopurified from the cell lysates and culture medium and electrophoresed on SDS 2\% agarose gels, and autoradiograms were prepared. Lysates of cells incubated in ammonium chloride showed only dimeric vWf and lacked the high molecular weight $(H M W)$ multimers present in control cells. Similarly, the culture medium of control cells contained a full range of vWf multimers, whereas cells cultured in ammonium chloride showed concentrationdependent loss of all multimeric forms larger than dimer. ing cell spreading, we prepared EC lacking Weibel-Palade bodies by culturing them for $3 \mathrm{~d}$ in ammonium chloride $(5,10,25$ $\mathrm{mM}$ ) followed by immunofluorescence staining for vWf (Fig. 7). Cells grown in the absence of ammonium chloride showed typical rod-shaped Weibel-Palade bodies (Fig. $7 a$ ), whereas they were absent in EC cultured in $25 \mathrm{mM}$ ammonium chloride (Fig. 7 b). Electrophoretic analysis of immunopurified, metabolically labeled vWf from EC lysates and media (Fig. 8) confirmed the absence of high molecular weight forms of vWf normally stored in Weibel-Palade bodies. Only vWf dimers were found in cell lysates and media of cells grown in ammonium chloride, whereas the full range of $\mathrm{vWf}$ multimers was found in controls. Despite the absence of Weibel-Palade bodies and high molecular weight vWf, cells cultured in ammonium chloride showed a mean of $72 \%$ spreading (duplicate samples) on coverslips coated with thrombin-made fibrin. This was similar to the mean of $79 \%$ spreading (duplicate samples) on fibrin prepared with thrombin using untreated EC, indicating that the promotion of EC spreading associated with FPB cleavage was not dependent on stimulated release of vWf.

\section{Discussion}

Fibrins varying in structure at the amino-terminal ends of the $A \alpha$ and $B \beta$ chains were prepared to identify structural features needed to support EC spreading. The results indicate that EC spreading on uncross-linked fibrin requires cleavage of FPB and involves residues $15-42$ of the $\beta$ chain. Cells adhered but failed to spread on fibrin prepared with reptilase, a snake venom which cleaves FPA but not FPB, whereas EC spreading was high on fibrin prepared with thrombin, which cleaves both FPA and FPB. Fibrin prepared with both enzymes also supported cell spreading, indicating that reptilase was not inhibitory. Cell spreading on thrombin-made fibrin was not mediated by cleaved FPB incorporated into the fibrin clot, since fibrin prepared by reptilase cleavage of fibrinogen in a solution 
containing fibrinopeptides did not support EC spreading. The role of the new amino terminus of the $\beta$ chain was investigated by using protease III from Crotalus atrox to specifically cleave B $\beta 1-42$ from fibrinogen, producing fibrinogen 325 , lacking both FPB and $\beta 15-42$. Fibrin prepared by thrombin cleavage of this modified fibrinogen supported minimal spreading, indicating that residues $15-42$ of the $\beta$ chain are needed to mediate spreading on a fibrin clot. The requirement for FPB cleavage to support spreading was not unique to $\mathrm{EC}$ but was also seen with cultured primary fibroblasts.

Several approaches were used to exclude the possibility that proteins other than fibrin contributed to the EC spreading observed on the fibrin surface. Plasma fibronectin, which was present in the original fibrinogen preparation, can mediate EC adhesion and spreading through an RGDS interaction with integrin $\alpha_{5} \beta_{1}$ (31). Also, Grinnell and colleagues (32) reported that incorporation of fibronectin into fibrin was required for baby hamster kidney cell adhesion and spreading on a coating of fibrin, and factor $\mathrm{XIII}_{\mathrm{a}}$-mediated cross-linking of fibronectin into fibrin caused enhanced cell adhesion and spreading. However, we found that uncrosslinked fibrin prepared by thrombin cleavage of either fibronectin-depleted fibrinogen or fibronectin-depleted fibrinogen to which supplemental fibronectin $(30 \mu \mathrm{g} / \mathrm{ml})$ was added supported equal EC spreading. Also, fibronectin in fibrin prepared by reptilase in the absence of cross-linking did not support EC spreading, even though the same concentration of fibronectin when used to coat a plastic surface did support spreading. Furthermore, addition of 0.5 $\mathrm{U} / \mathrm{ml}$ reptilase to the fibronectin coating did not lower the high spreading observed on the fibronectin coated surface, indicating that reptilase did not adversely affect the site(s) on fibronectin responsible for mediating cell spreading. These results suggest that EC preferentially interact with the fibrin component of a clot containing both fibrin and fibronectin, possibly due to the higher relative fibrin concentration. Moreover, this indicates that the presence of fibronectin in the absence of FPB cleavage was insufficient to support spreading.

Exposure of EC to enzymatically active thrombin at a concentration of $0.1 \mathrm{U} / \mathrm{ml}\left(8 \times 10^{-10} \mathrm{~mol} /\right.$ liter $)$ or greater has been shown to cause cell contraction $(12,33)$, and a decrease in unpolymerized actin associated with increased formation of stress fibers was found after exposure to $2 \mathrm{U} / \mathrm{ml}$ (33). In our cell spreading experiments, we prepared fibrin using a thrombin concentration of $0.5 \mathrm{U} / \mathrm{ml}$, and $<1 \%$ bound to the surface, resulting in the incorporation of $<1 \times 10^{-14} \mathrm{~mol}(0.001 \mathrm{U})$ per well or slide. This is well below the concentrations observed to cause EC shape change and is also less than that needed to activate EC which occurs at concentrations of $0.01 \mathrm{U} / \mathrm{ml}$ or greater (34-41). Moreover, the activity of this residual thrombin in our studies was further reduced by adding to the fibrincoated surfaces excess hirudin or PPACK, specific high-affinity thrombin inhibitors that have been shown to be effective in inhibiting fibrin-bound thrombin (42). Such thrombin-made fibrins incubated with hirudin or PPACK still supported EC spreading. Furthermore, experiments with fibrinogen 325 also indicated that direct effects of thrombin on EC could not explain the observed differences in EC spreading observed on fibrins. The secondary binding site for thrombin on fibrin is located in the $\mathrm{E}$ domain and includes residues $\beta$ (val55met 118 ), located beyond the $\beta 42-43$ cleavage site of protease III $(43,44)$. Consistent with this location, there was equal binding of thrombin to fibrin 325 compared to fibrin prepared from intact fibrinogen. However, this modified fibrin supported only minimal spreading that was consistent with the small residual amount of undegraded $\beta$ chain present in the preparation (Fig. 5).

We also investigated the possible role of other sites on the thrombin molecule, distinct from the thrombin catalytic center, in promoting spreading of EC on fibrin. The thrombin $\beta$ chain has an RGD site at residues $187-189$ preceded by a tyrosine at position 186 (45). A thrombin derivative, formed by nitration of the tyrosine residue, has been shown to promote EC adhesion and spreading through $\alpha_{\mathrm{v}} \beta_{3}$ in an RGD-dependent manner, although native $\alpha$-thrombin supported minimal adhesion (46). To evaluate the possible role of the thrombin RGD site or other noncatalytic sites in mediating cell spreading, PPACK was used to inactivate the catalytic site, and the PPACK-thrombin complex was incorporated into fibrin made with reptilase. This fibrin surface failed to support spreading, indicating that neither the thrombin RGD site nor any other site distinct from the catalytic center was a sufficient stimulus.

Release of vWf from Weibel-Palade bodies of EC could potentially contribute to cell spreading on fibrin prepared with thrombin, since vWf release is stimulated from cells exposed on their nonadherent surface to fibrin (14), possibly through recognition of $\beta 15-42$ by a non-integrin receptor (47). However, the difference in EC spreading observed on fibrin prepared with thrombin compared to that made with reptilase was maintained using EC depleted of Weibel-Palade bodies (Fig. 7 b). Also, early passage fibroblasts, which do not synthesize vWf, spread on fibrin prepared with thrombin but not on fibrin prepared with reptilase, indicating that promotion of EC spreading by FPB cleavage and exposure of the new amino terminus of the $\beta$ chain was not dependent on $\mathrm{vWf}$ release.

The adhesion of EC to fibrinogen is mediated through RGD sites that interact with the integrin receptor $\alpha_{\mathrm{v}} \beta_{3}(1,48$, 49). The fibrinogen molecule has two RGD sequences on each $\mathrm{A} \alpha$ chain, one located in the central E-domain and a second near the $A \alpha$ carboxyl terminus at residues 572-574. Cheresh et al. (48) have found that adhesion of EC to fibrinogen is mediated only by the carboxyl-terminal RGD site. Our results of adhesion on fibrin are consistent with this observation, since adhesion was equivalent on fibrin prepared with either reptilase or thrombin (Fig. 3) both of which had intact $A \alpha$ chains (Fig. 4). In contrast, the spreading of EC on immobilized fibrinogen-coated surfaces appears to be mediated differently from EC spreading on fibrin. Fibrinogen immobilized on a plastic surface undergoes conformational changes exposing epitopes not accessible in soluble fibrinogen (49). These changes may alter its interaction with other proteins including cell receptors, since immobilized fibrinogen binds to unactivated glycoprotein IIbIIIa whereas soluble fibrinogen does not $(50)$. We would hypothesize that sites which can support spreading are accessible on plastic-immobilized fibrinogen because of the conformational changes that accompany surface binding, but these sites are not accessible on polymerized fibrin lacking FPB cleavage. Our findings indicate that unlike spreading on fibrin, residues $\beta 15-42$ are not needed for spreading on a fibrinogen coating, since we observed active spreading on slides coated with fibrinogen 325 which lacks both FPB and $\beta 15-42$. Dejana et al. (10) have observed EC spreading on surfaces coated with fibrinogen, but found this spreading to be blocked by treatment with emetine or monensin, and suggested that synthesis and secretion of cellular fibronectin is required for spreading to 
occur. We have not investigated the possible role of cell secreted protein in promoting cell spreading on fibrin. However, our studies demonstrate that cell spreading occurred on polymerized fibrin only after cleavage of FPB and required residues $15-42$ of the $\beta$ chain, and that plasma fibronectin was not required.

The involvement of separate sites in mediating cell adhesion and spreading has been found with other adhesive glycoproteins including laminin and thrombospondin. For example, EC adherence to laminin is mediated through an RGD interaction with the integrin receptor $\alpha_{2} \beta_{1}$, but spreading results from interaction between the non-integrin receptor LB69 and the peptide sequence YIGRSR located on a separate polypeptide chain (2). Additionally, the interaction of melanoma cells with thrombospondin involves two separate sites, with cell attachment mediated through an RGD containing carboxyl-terminal domain, while spreading requires an additional interaction with an amino-terminal heparin-binding domain (51).

Cleavage of fibrinopeptides from fibrinogen by thrombin is a central event in hemostasis leading directly to fibrin polymerization. Cleavage of FPA occurs rapidly, exposes a polymerization site at the amino terminus of the $\alpha$ chain (52), and can result in fibrin polymerization without FPB cleavage as demonstrated by the action of reptilase (53). Cleavage of FPB by thrombin occurs more slowly $(54,55)$, and exposes a secondary polymerization site that accelerates fibrin polymerization (56) and contributes to lateral organization of fibrin protofibrils (57). Additionally cleavage of FPB exposes a fibrin specific epitope, $\beta 15-21$, for which monoclonal antibodies have been identified $(58,59)$. More recent analysis indicates that the amino terminus of the fibrin $\beta$ chain $(\beta 15-55)$ undergoes a significant conformational change after FPB cleavage, bringing noncontiguous amino acids into proximity and forming the polymerization site (56). Thus, cleavage of fibrinopeptides not only results in formation of polymerized fibrin, but may also result in conformational changes and expose fibrin-specific sites important for modulation of cellular responses.

Peptides resulting from cleavage of the amino terminus of the $\mathrm{B} \beta$ chain by thrombin or plasmin have been shown to exert several effects on cells involved in hemostasis and inflammation. FPB has been reported to have vasoconstrictor activity (60), to stimulate migration of inflammatory cells including fibroblasts and neutrophils $(61,62)$ and to cause a change in EC morphology (63). Plasmin hydrolyses the arg42-ala43 and the lys 47-ala48 bonds, liberating the peptide $\mathrm{B} \beta 1-42$ from fibrinogen and $\beta 15-42$ from fibrin and also forming the small peptide $\beta 43-47$. The latter stimulates vasodilation and increased vascular permeability $(60,64,65)$. B $\beta 1-42$ may stimulate cell migration $(61,62)$, and $\beta 15-42$ induces $v W f$ release from $\mathrm{EC}(66)$ and also inhibits platelet aggregation (67). Our results indicate that $\beta 15-42$, after FPB cleavage, is also involved in stimulating EC spreading on a fibrin clot. Together, these findings demonstrate that cleavage of the fibrin $B \beta$ chain plays an important role in cellular interactions with fibrin.

\section{Acknowledgments}

We acknowledge the expert technical assistance of Sherry Sabo, Janice White, Melissa Primavera, and Rachel Goss and the help of Carol Weed in the preparation of the manuscript.
This work was supported in part by grants HL-30616 and HL07152 from the National Heart, Lung and Blood Institute, National Institutes of Health, Bethesda, Maryland.

\section{References}

1. Cheng, Y. F., and R. H. Kramer. 1989. Human microvascular endothelial cells express integrin-related complexes that mediate adhesion to the extracellular matrix. J. Cell. Physiol. 139:275-286.

2. Basson, C. T., W. J. Knowles, L. Bell, S. M. Abelda, V. Castronova, L. A. Liotta, and J. A. Madri. 1990. Spatiotemporal segregation of endothelial cell integrin and nonintegrin extracellular matrix-binding proteins during adhesion events. J. Cell Biol. 110:789-801.

3. Abelda, S. M., D. Daise, E. M. Levine, and C. A. Buck. 1989. Identification and characterization of cell-substratum adhesion receptors on cultured human endothelial cells. J. Clin. Invest. 83:1992-2002.

4. Languino, L. R., K. R. Gehlsen, E. Waynor, W. G. Carter, E. Engvall, and E. Ruoslahti. 1989. Endothelial cells use $\alpha_{2} \beta_{1}$ integrin as a laminin receptor. $J$. Cell Biol. 109:2455-2461.

5. Kramer, R. H., Y. F. Cheng, and R. Clyman. 1990. Human microvascular endothelial cells use $\beta_{1}$ and $\beta_{3}$ integrin receptor complexes to attach to laminin. $J$. Cell Biol. 111:1233-1234.

6. Dejana, E., M. G. Lampugnani, M. Giogi, M. Gaboli, A. B. Federici, E. M. Ruggeri, and P. C. Marchiso. 1989. Von willebrand factor promotes endothelial adhesion via an Arg-Gly-Asp-dependent mechanism. J. Cell Biol. 109:367-375.

7. Taraboletti, G., D. Roberts, L. Liotta, and R. Giavazzi. 1990. Thrombospondin modulates endothelial cell adhesion, motility and growth: A potential angiogenesis regulatory factor. J. Cell Biol. 111:765-772.

8. Murphy-Ullrich, J. E., and M. Hook. 1989. Thrombospondin modulates focal adhesions in endothelial cells. J. Cell Biol. 109:1304-1319.

9. Cheresh, D. A. 1987. Human endothelial cells synthesize and express an Arg-Gly-Asp-directed adhesion receptor involved in attachment to fibrinogen and von Willebrand factor. Proc. Natl. Acad. Sci. USA. 84:6471-6475.

10. Dejana, E., M. G. Lampugnani, M. Giorgi, M. Gaboli, and P. C. Marchiso. 1990. Fibrinogen induces endothelial cell adhesion and spreading via the release of endogenous matrix proteins and the recruitment of more than one integrin receptor. Blood. 75:1509-1517.

11. Languino, L. R., S. Collela, A. Andrieux, J. J. Ryckewaert, M. H. Charon, P. C. Marchisio, E. F. Plow, M. H. Ginsberg, G. Marguerie, and E. Dejana. 1989. Fibrinogen-endothelial cell interaction in vitro. A pathway mediated by an ArgGly-Asp recognition specificity. Blood. 73:734-742.

12. Weimer, B., and B. Delvos. 1986. The mechanism of fibrin-induced disorganization of cultured human endothelial cell monolayers. Arteriosclerosis. 6:139-145.

13. Kadish, J. L., C. E. Butterfield, and J. Folkman. 1979. The effect of fibrin on cultured vascular endothelial cells. Tissue Cell. 11:99-108.

14. Ribes, J. A., C. W. Francis, and D. D. Wagner. 1987. Fibrin induced release of von Willebrand factor from endothelial cells. J. Clin. Invest. 79:117123.

15. Ruoslahti, E. 1991. Integrins. J. Clin. Invest. 87:1-5.

16. Smith, J. W., and D. A. Cheresh. 1990. Integrin $\left(\alpha_{\mathrm{v}} \beta_{3}\right)$-ligand interaction. J. Biol. Chem. 265:2168-2172.

17. Burridge, K., K. Fath, T. Kelly, G. Nuckolls, C. Turner. 1988. Focal adhesions: transmembrane junctions between the extracellular matrix and the cytoskeleton. Annu. Rev. Cell Biol. 4:487-525.

18. Wong, M. K. K., and A. Gotlieb. 1988. The reorganization of microfilaments, centrosomes, and microtubules during in vitro small wound reendothelialization. J. Cell Biol. 107:1777-1783.

19. Pandya, B. V., C. S. Cierniewski, and A. Z. Budzynski. 1985. Conservation of the human fibrinogen conformation after cleavage of the $\mathrm{B} \beta$ chain $\mathrm{NH}_{2}$ terminus. J. Biol. Chem. 260:2994-3000.

20. Pandya, B., and A. Z. Budzynski. 1984. Anticoagulant protease from Western Diamondback rattlesnake (Crotalus atrox) venom. Biochemistry. 23:460-470.

21. Schwartz, M. L., S. V. Pizzo, R. L. Hill, and P. A. McKee. 1971. The effect of fibrin-stabilizing factor on the subunit structure of human fibrin. J. Clin. Invest. 50:1506-1513.

22. Engvall, E., and E. Ruoslahti. 1977. Binding of soluble form of fibroblast surface protein, fibronectin, to collagen. Int. J. Cancer 20:1-5.

23. Weber, K., and M. Osborn. 1969. The reliability of molecular weight determinations by dodecyl sulfate-polyacrylamide gel electrophoresis. J. Biol. Chem. 244:4406-4412.

24. Marchalonis, J. J. 1969. An enzymatic method for the trace iodination of immunoglobulins and other proteins. Biochem. J. 113:299-305.

25. Wagner, D. D., J. B. Olmsted, and V. J. Marder. 1982. Immunolocalization of von Willebrand protein in Weibel-Palade bodies of human endothelial cells. J. Cell Biol. 95:355-360. 
26. Gimbrone, M., R. Cotran, and J. Folkman. 1974. Human vascular endothelial cells in culture: growth and DNA synthesis. J. Cell Biol. 60:673-684.

27. Kaminski, M., and J. McDonagh. 1987. Inhibited thrombins. Interactions with fibrinogen and fibrin. Biochem. J. 242:881-887.

28. Collen, D., O. Matsuo, J. M. Stassen, C. Kettner, and E. Shaw. 1982. In vivo studies of a synthetic inhibitor of thrombin. J. Lab. Clin. Med. 99:76-83.

29. Wagner, D. D., and V. J. Marder. 1984. Biosynthesis of von Willebrand protein by human endothelial cells: processing steps and their intracellular localization. J. Cell Biol. 99:2123-2130.

30. Sporn, L. A., V. J. Marder, and D. D. Wagner. 1986. Inducible secretion of large, biologically potent von Willebrand factor multimers. Cell. 46:185-190.

31. Dejana, E., S. Colella, G. Conforti, M. Abbadini, M. Gaboli, and P. C. Marchiso. 1988. Fibronectin and vitronectin regulate the organization of their respective Arg-Gly-Asp adhesion receptors in cultured human endothelial cells. $J$. Cell Biol. 107:1215-1223.

32. Grinnell, F., M. Feld, and D. Minter. 1980. Fibroblast adhesion to fibrinogen and fibrin substrata: requirement for cold-insoluble globulin (plasma fibronectin). Cell. 19:517-525.

33. Galdal, K., S. Eversen, A. Hoglund, and E. Nilsen. 1984. Actin pools and actin microfilament organization in cultured human endothelial cells after exposure to thrombin. Br. J. Haematol. 58:617-625.

34. Daniel, T. O., V. C. Gibbs, D. F. Mifay, M. R. Garovoy, and L. T. Williams. 1986. Thrombin stimulates c-sis gene expression in microvascular endothelial cells. J. Biol. Chem. 261:9579-9582.

35. Lampugnani, M. G., F. Colotta, N. Polentarutti, M. Pedenovi, A. Mantovani, and E. Dejana. 1990. Thrombin induces c-fos expression in cultured human endothelial cells by a $\mathrm{Ca}^{2+}$-dependent mechanism. Blood. 76:1173-1180.

36. Harlan, J. M., P. J. Thompson, R. R. Ros, and D. F. Bowen-Pope. 1986. $\alpha$-Thrombin induces release of platelet derived growth factor-like molecule(s) by cultured endothelial cells. J. Cell Biol. 103:1129-1133.

37. Levin, E. G., and L. Santell. 1991. Thrombin- and histamine-induced signal transduction in human endothelial cells. J. Biol. Chem. 226:174-181.

38. Bartha, K., R. Müller-Peddinghaus, L. A. A. Van Rooijen. 1989. Bradykinin and thrombin effects on polyphosphoinositide hydrolysis and prostacyclin production in endothelial cells. Biochem. J. 263:149-155.

39. Levin, E. G., and L. Santell. 1988. Stimulation and desensitization of tissue plasminogen activator release from human endothelial cells. J. Biol. Chem. 263:9360-9365.

40. Levin, E. G., V. Marzec, J. Anderson, and L. A. Harker. 1984. Thrombin stimulates tissue plasminogen activator release from cultured human endothelia cells. J. Clin. Invest. 74:1998-1995.

41. Hattori, R., K. K. Hamilton, R. D. Fogates, R. P. McEver, and P. J. Sims. 1989. Stimulated secretion of endothelial $\mathrm{vWf}$ is accompanied by rapid redistribution to the cell surface of the intracellular granule membrane protein GMP140. J. Biol. Chem. 264:7768-7771.

42. Weitz, J. I., M. Hudoba, D. Massel, J. Maraganore, and J. Hirsh. 1990. Clot-bound thrombin is protected from inhibition by heparin-antithrombin II but is susceptible to inactivation by antithrombin III-independent inhibitors. $J$. Clin. Invest. 86:385-391.

43. Vali, Z., and H. A. Scheraga. 1988. Localization of the binding site on fibrin for the secondary binding site of thrombin. Biochemistry. 27:1956-1963.

44. Kaczmarek, E., and J. McDonagh. 1988. Thrombin binding to the A $\alpha$-, and $B \beta$-, and $\gamma$ chains of fibrinogen and to their remnants contained in Fragment E. J. Biol. Chem. 236:13896-13900.

45. Furie, B., D. H. Bind, R. J. Feldmann, D. J. Robinson, J. P. Burnies, and B. C. Furie. 1982. Computer-generated models of blood coagulation factor $\mathrm{X}_{\mathrm{a}}$, factor $\mathrm{IX}_{\mathrm{a}}$ and thrombin based upon structural homology with other serine proteases. J. Biol. Chem. 257:3875-3882.

46. Bar-Shavit, R., V. Sabbah, M. G. Lampugnani, P. C. Marchisio, J. W. Fenton, I. Vlodavsky, and E. Dejana. 1991. An Arg-Gly-Asp sequence within thrombin promotes endothelial cell adhesion. J. Cell Biol. 112:335-344.
47. Erban, J. K., and D. Wagner. 1989. Human umbilical vein endothelial cells possess surface receptors which bind to amino acids $15-42$ of the $B \beta$ chain of fibrinogen. Blood. 74s:212a. (Abstr.)

48. Cheresh, D. A., S. A. Berliner, V. Vicente, and Z. M. Ruggeri. 1989. Recognition of distinct adhesive sites on fibrinogen by related integrins on platelets and endothelial cells. Cell. 58:945-953.

49. Zamarron, C., M. H. Ginsberg, and E. F. Plow. 1990. Monoclonal antibodies specific for a conformationally altered state of fibrinogen. Thromb. Haemostasis. 64:41-46.

50. O’Toole, T. E., J. C. Loftus, X. Du, A. A. Glass, Z. M. Ruggeri, S. J. Shattil, E. F. Plow, and M. H. Ginsberg. 1990. Affinity modulation of the alpha IIb beta 3 integrin (platelet GPIIb-IIIa) is an intrinsic property of the receptor. Cell Regul. 1:883-893.

51. Roberts, D. D., J. A. Sherwood, and V. Ginsburg. 1987. Platelet thrombospondin mediates attachment and spreading of human melanoma cells. J. Cell Biol. 104:131-139.

52. Laudano, A. P., and R. F. Doolittle. 1978. Synthetic peptide derivatives that bind to fibrinogen and prevent polymerization of fibrin monomers. Proc Natl. Acad. Sci. USA. 75:3085-3089.

53. Blombäck, B., M. Blombäck, and I. M. Nilsson. 1957. Coagulation studies on "Reptilase", an extract of the venom from Bothrops jararaca. Thromb. Diath. Haemorrh. 1:76-86.

54. Bailey, K., F. R. Bettelheim, L. Lorand, and W. R. Middlebrook. 1951 Action of thrombin in the clotting of fibrinogen. Nature (Lond.). 167:233-234.

55. Martinelli, R. A., and H. A. Scheraga. 1980. Steady state kinetic study of the bovine thrombin-fibrinogen interaction. Biochemistry. 19:2343-2350.

56. Pandya, B., J. Garbiel, J. O'Brien, and A. Budzynski. 1991. Polymerization site in the $\beta$ chain of fibrin: mapping of the $B \beta 1-55$ sequence. Biochemistry 30:162-168.

57. Weisel, J. W. 1986. Fibrin assembly. Lateral aggregation and the role of the two pairs of fibrinopeptides. J. Biophys. Soc. 50:1079-1084.

58. Kudryk, B., A. Rohoza, M. Ahadi, J. Chin, and M. E. Wiebe. 1984. Specificity of a monoclonal antibody for the $\mathrm{NH}_{2}$-terminal region of fibrin. $\mathrm{Mol}$. Immunol. 21:89-94.

59. Hui, K. Y., E. Haber, and G. R. Matsueda. 1983. Monoclonal antibodies to a synthetic fibrin-like peptide bind to human fibrin but not fibrinogen. Science (Wash. DC). 222:1129-1132.

60. Belew, M., B. Gerdin, J. Porath, and T. Saldeen. 1978. Isolation of vasoactive peptides from human fibrin and fibrinogen degraded by plasmin. Thromb. Res. 13:983-994.

61. Skogen, W. F., R. M. Senior, G. L. Griffin, and G. D. Wilner. 1988. Fibrinogen-derived peptide $B \beta 1-42$ is a multidomained neutrophil chemoattractant. Blood. 71:145-149.

62. Senior, R. M., W. F. Skogen, G. L. Griffin, and G. D. Wilner. 1986. Effects of fibrinogen derivatives upon the inflammatory response: studies with human fibrinopeptide B. J. Clin. Invest. 77:1014-1019.

63. Rowland, F. N., M. J. Donovan, P. T. Picciano, G. D. Wilner, and D. L. Kreutzer. 1984. Fibrin mediated vascular injury identification of fibrin peptides that mediate endothelial cell retraction. Am. J. Pathol. 117:418-428.

64. Anderson, R. G., K. Saldeen, and T. Saldeen. 1983. A fibrin(ogen) derived penta peptide induces vasodilation, prostacycline release and an increase in cyclic AMP. Thromb. Res. 30:213-218.

65. Gerdin, B., G. Lindenberg, V. Ragnarsson, T. Saldeen, and R. Wallin. 1983. Structural requirements for microvascular permeability-increasing ability of peptides: studies on analogues of a fibrinogen pentapeptide fragment. Biochim. Biophys. Acta. 757:366-370.

66. Ribes, J. A., F. Ni, D. D. Wagner, and C. W. Francis. 1989. Mediation of fibrin-induced release of von Willebrand factor from cultured endothelial cells by the fibrin $\beta$ chain. J. Clin. Invest. 84:435-442.

67. Chen, C. S., S. H. Chou, and P. Thiagarajan. 1988. Fibrin(ogen) peptide B $\beta 15-42$ inhibits platelet aggregation and fibrinogen binding to activated platelets. Biochemistry. 27:6121-6126. 